\title{
De preterida a preferida: considerações em torno da trajetória intelectual de Alice Piffer Canabrava (1935-1951)*
}

\author{
From neglected to preffered: considerations on the intellectual trajectory \\ of Alice Piffer Canabrava (1935-1951)
}

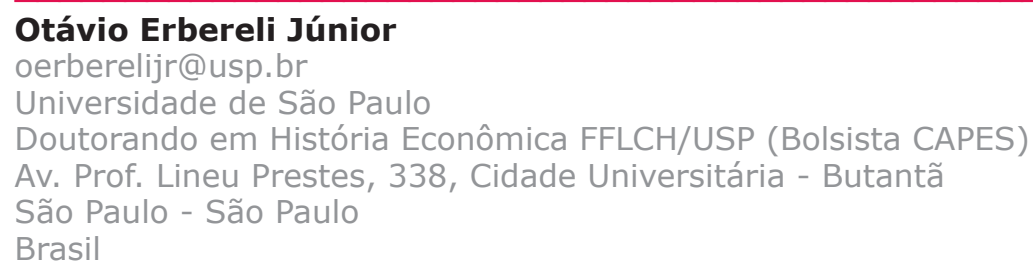

\section{Resumo}

Este artigo tem o objetivo de apresentar sinteticamente que a recuperação profissional da historiadora Alice Piffer Canabrava após a derrota no concurso para a cátedra de História da Civilização Americana, realizado em 1946, deveu-se a uma dupla conformação de fatores: a cultura acadêmica peculiar da Faculdade de Filosofia, Ciências e Letras da Universidade de São Paulo (FFCL-USP) em suas décadas iniciais e a arraigada concepção da época acerca do lugar da mulher na sociedade. Em contrapartida, seu ingresso e sucesso na Faculdade de Ciências Econômicas e Administrativas (FCEA) da mesma Universidade podem ser explicados pela cultura acadêmica distinta deste espaço. Para corroborar tal visão, também comparamos a trajetória de Alice Canabrava com a de outras mulheres que partilhavam de uma mesma ambientação institucional.

\section{Palavras-chave}

Alice Piffer Canabrava; História intelectual; História da historiografia brasileira.

\begin{abstract}
This article intends to demonstrate, in summary, that Alice Piffer Canabrava's defeat in the contest for the American Civilization History chair, taken place in 1946, was due to two factors: a peculiar academic culture of the University of São Paulo's School of Philosophy, Sciences and Languages in its early decades and an ingrained conception regarding women's place in society. On the other hand, her entering and success at the School of Economic and Administrative Sciences at USP can be explained by a distinct academic culture of that place. To support this outlook, the trajectory of Alice Canabrava is compared to that of other women who also shared an institutional setting.
\end{abstract}

\section{Keywords}

Alice Piffer Canabrava; Intellectual history; History of Brazilian historiography.

Recebido em: 16/10/2016

Aprovado em: 20/12/2016

* Agradeço a leitura atenta e as sugestões generosas da Profa. Dra. Raquel Glezer (FFLCH/USP). 
Alice Piffer Canabrava (1911-2003) formou-se na Escola Normal Caetano de Campos, em São Paulo, em 1930, tendo recebido o diploma de "habilitação para o magistério público em São Paulo" e o prêmio Barão do Rio Branco, concedido ao aluno com as maiores notas em História e Geografia obtidas nos cinco anos de curso (CANABRAVA 1946, p. 1). Foi professora do curso primário entre 1931 e 1935 em Araras (SP), cidade onde nascera, e em 1935 ingressou no curso de Geografia e História da Faculdade de Filosofia, Ciências e Letras (FFCL) da Universidade de São Paulo (USP) por comissionamento. ${ }^{1}$ Dois anos depois, fez parte da segunda turma de formados da FFCL, com distinção na cadeira de História da Civilização.

Em maio de 1938, foi convidada pelo regente da cadeira de História da Civilização Americana, Paul Vanorden Shaw, para exercer a função de assistente adjunto de $2^{a}$ categoria. No ano seguinte passou às funções de assistente adjunto de $1^{\circ}$ categoria e em 1942 logrou a posição de $1^{\text {a }}$ assistente em tempo parcial, após ter defendido a tese de doutoramento intitulada "O Comércio Português no Rio da Prata (1580-1640)", orientada por Jean Gagé e aprovada pela banca examinadora com distinção (CANABRAVA 1944). Em 1946, ao submeter-se ao concurso para a cadeira de História da Civilização Americana com a tese "A Indústria do Açúcar nas Ilhas Inglesas e Francesas do Mar das Antilhas (1697-1755)" (CANABRAVA 1981), não conseguiu a cátedra, mas obteve o título de livre-docente. ${ }^{2}$ Ainda em 1946, com a fundação da Faculdade de Ciências Econômicas e Administrativas (FCEA) da USP, foi contratada por um ano como Técnica de Administração do Instituto de Administração para o setor de pesquisa histórica (CANABRAVA 1991, p. 2), sendo assentada ao final do prazo. Passou, então, a reger a cadeira de História Econômica da FCEA, tornando-se a primeira mulher catedrática da USP, via concurso de provas e títulos, em 1951, com a tese "O Desenvolvimento da Cultura do Algodão na Província de São Paulo (1861-1875)" (CANABRAVA 2011). 3

Em paralelo à carreira na USP, suas outras atividades acadêmicas envolveram a participação na Associação dos Professores de História do Ensino Superior (APUH), atual Associação Nacional de História (ANPUH), desde sua fundação, ocorrida na FFCL de Marília (SP), em 1961; a atuação como sócia efetiva do Instituto Histórico e Geográfico de São Paulo (IHGSP), sócia correspondente do Instituto Histórico e Geográfico Brasileiro (IHGB) e sócia efetiva da Academia Paulista de História, na cadeira "André João Antonil"; e o papel de fundadora, em 1981, da Revista Brasileira de História. Em 1986, foi eleita professora emérita da USP, coroando uma trajetória intelectual vitoriosa para uma "professorinha do interior" (CANABRAVA 2005, p. 23-34). ${ }^{4}$ Em um ambiente predominantemente masculino e de tradição bacharelesca, isto não era pouco.

\footnotetext{
${ }^{1}$ Em 1935, frente ao pequeno número de matriculados no segundo ano dos cursos da $F F C L$, o governo estadual abriu edital para que os professores que tivessem cursado Escola Normal pudessem ingressar na FFCL por meio de uma prova e com vencimentos, contanto que mantivessem boas notas ao longo do curso. 2 Tal titulação era conferida aos candidatos que obtivessem nota superior a sete, mesmo que preteridos para a cátedra.

${ }^{3}$ A primeira edição desta tese foi publicada pela Indústria Gráfica Siqueira, em 1951, e a segunda pela editora T. A. Queiroz, em 1984.

${ }_{4}^{4}$ Caracterização feita por Alice Canabrava em depoimento em sessão organizada pelo Centro de Estudos Rurais e Urbanos (CERU), ocorrida na reunião anual da Sociedade Brasileira para o Progresso da Ciência (SBPC), em julho de 1984.
} 
O que se pretende demonstrar aqui é que o insucesso da profa Canabrava no referido concurso de cátedra na FFCL em 1946 deveu-se à cultura acadêmica peculiar da instituição, somada ao papel atribuído à mulher na sociedade da época, ao qual a Universidade não poderia estar imune. ${ }^{5}$ Buscamos comprovar esta hipótese por meio da análise de três momentos de sua trajetória. Em primeiro lugar, a seção intitulada "'Garantia de sucesso' da tese doutoral" indica como a operação historiográfica da autora já estava coadunada a uma compreensão historiográfica cara aos intelectuais e professores renomados do período. Realçamos especialmente as concepções metódicas reelaboradas de Afonso Taunay (1876-1958), ${ }^{6}$ realce justificado também pelo fato de ter acompanhado muito de perto o desenvolvimento intelectual de Alice Canabrava, desde os tempos em que fora sua aluna no curso de História da Civilização Brasileira até a obtenção da cátedra na FCEA.

Depois, na seção intitulada "O Concurso", entendemos que Alice Canabrava possivelmente foi vítima de uma articulação masculina naquela ocasião. Dois pontos são significativos para uma tal compreensão: o sucesso de sua tese de doutoramento, em 1942, e as notas altas a ela atribuídas pelo prof. Sérgio Buarque de Holanda no concurso de 1946. Também realçamos a cultura acadêmica de cunho "bacharelesco" e totalmente pertinente àquele momento, não por acaso utilizada como justificativa legitimadora da vitória dada ao candidato concorrente. Por fim, em "A (con)sagração na Faculdade de Ciências Econômicas e Administrativas", buscamos demonstrar que o elemento fundamental para que a profa Canabrava alcançasse a condição de catedrática, além de sua comprovada competência acadêmica, foi exatamente este novo espaço, a FCEA e, sobretudo, sua cultura acadêmica distinta daquela que marcava a FFCL.

\section{"Garantia de sucesso" na tese doutoral}

Nos arquivos da FFLCH/USP encontra-se uma ficha que sintetiza a ata do doutoramento da profa Alice Canabrava na cadeira de História da Civilização Americana. O trabalho intitulado "O Comércio Português no Rio da Prata (1580-1640)" foi apresentado no dia 13 de novembro de 1942 e, aprovado com distinção, recebeu nota 9,56 da comissão examinadora, composta pelos professores Jean Gagé (presidente da banca e seu orientador), Plínio Ayrosa, Pierre Monbeig, Alfredo Ellis Júnior e Eurípedes Simões de Paula.

O professor Jean Gagé chegara à antiga FFCL em 1938, para substituir Fernand Braudel na cadeira de História da Civilização. Antes de retornar à França, Braudel escreveu uma carta ao diretor da Faculdade recomendando três alunos em especial: Eduardo D'Oliveira França, Alice Piffer Canabrava e Risoleta Violante Pereira, que já haviam escolhido os temas de suas teses. O de Alice

\footnotetext{
5 Utilizamos aqui a noção de "cultura acadêmica" elaborada por Fritz Ringer, que a define como "a rede de convicções inter-relacionadas e explícitas acerca das práticas acadêmicas de ensinar, aprender e pesquisar, bem como sobre os significados sociais dessas práticas" (no original: "the network of interrelated and explicit beliefs about the academic practices of teaching, learning, and research, and about the social significances of these practices") (RINGER 1992, p. 13).

${ }^{6}$ Afonso d'Escragnolle Taunay foi diretor do Museu Paulista entre 1917 e 1945 e professor da FFCL/USP de 1934 a 1937, dentre outros ofícios afins.
} 
Canabrava seria "O papel de Lisboa na história de Portugal e particularmente nas grandes descobertas marítimas". Braudel, que demonstrava conhecer o trabalho dos três recém-formados, encerrou a recomendação com os seguintes dizeres: "Sou partidário do comissionamento eventual desses estudantes, pois seus trabalhos anteriores são uma garantia de sucesso".7

Seja pela orientação de Jean Gagé, seja por ter obtido acesso a outra documentação, relacionada não a Lisboa e sim a Buenos Aires, Alice Canabrava não levou adiante a pesquisa projetada por Braudel. Em suas reminiscências, e correndo todos os riscos subjacentes à utilização deste tipo de relato, ela afirmou o seguinte:

No caso da tese de doutoramento, [...] lembro-me bem como tudo começou. No Museu Paulista, deparei-me com vários volumes dos Arquivos de Buenos Aires. [...]. Na defesa, o Prof. Gagé, oficialmente meu orientador, declarou que eu havia feito a tese sozinha e que o meu trabalho nada tinha dele (CANABRAVA 1997, p. 159).

Se Gagé parece não ter tido participação na tese de Canabrava, pelo menos através de orientação direta, outro membro da banca examinadora, Alfredo Ellis Júnior, representava uma importante conexão intelectual para a autora. Por um lado, Ellis Júnior substituíra Afonso Taunay (a quem admirava desde os tempos do Colégio São Bento, em São Paulo) na cadeira de História da Civilização Brasileira, em 1938, e tinha uma concepção de história muito próxima à do historiador das bandeiras paulistas; por outro, o próprio Taunay redigiria o prefácio da tese de doutoramento de Alice Canabrava - algo muito expressivo, uma vez que, para François Hartog, o leitor moderno está habituado a encontrar no prefácio um verdadeiro discurso do método.

O prefácio é também o lugar onde se acertam as contas: elas são calculadas ou pagas, as dívidas são reconhecidas ou negadas. É nele que se confessam, afloram ou se ignoram as relações com a instituição (em sentido preciso ou amplo), a qual autoriza e dá crédito (HARTOG 2001, p. 11).

Notamos que, no prefácio da tese de Alice Canabrava, a autorização que provém de Afonso Taunay concede à obra dupla legitimidade: a da tese e da autora.

Distinta aluna do curso que professei na Faculdade de Filosofia, de 1934 a 1937, tive o ensejo de atribuir-lhe alta nota de aprovação que mereceu no último ano deste quatriênio. Vi-a continuar sempre empolgada pelos estudos de História, frequentando de modo mais assíduo a biblioteca do Museu Paulista e a do Instituto Histórico de São Paulo (TAUNAY 1944, p. IX).

Já aposentada da FCEA (a atual Faculdade de Economia, Administração e Contabilidade - FEA), a profa Alice Canabrava recordar-se-ia de que sua tese fora mesmo fruto de suas visitas ao Museu Paulista. Contudo, ela não partiu de um 
problema já estabelecido para depois pesquisar no arquivo, procedimento este pertinente aos primeiros annalistes e sua história-problema (NOZOE, MELLO E SAES 1985); ao contrário, foi por ter encontrado vasta documentação sobre a Argentina colonial que lhe surgiu o tema:

[...] Encantei-me com o material, logo percebi que estava diante de um grande filão. Imediatamente comecei a copiar e a fazer o trabalho. Creio que levei um ano para realizá-lo. [...] Em certa medida, foi a fonte documental que inspirou minha pesquisa. Foi o primeiro amor. Eu gosto muito desse livro e até hoje eu o leio com prazer (CANABRAVA 1997, p. 159).

De volta ao prefácio de Taunay, o mestre, após perpassar rapidamente as três partes da tese, concluía afirmando que:

[...] Como excelente e honesta elaboração, agora desabrochada em inteligente realidade, é-me sobremodo grato cumprimentar a Autora de um trabalho efetuado sob as instigações das diretrizes norteadoras dos que escrevem história digna deste nome (TAUNAY 1944, p. XI).

Mas, o que seria para Taunay uma "história digna deste nome"? Não se pode, de saída, confundir sua atuação na cadeira de História da Civilização Brasileira da FFCL com seu método de escrita da história. Realmente, seus métodos de ensino eram bastante tradicionais quando comparados aos "mestres franceses", como a própria Alice Canabrava não deixou de lembrar (2005, p. 28). Por outro lado, vinculá-lo diretamente à Escola Metódica Francesa seria desconsiderar várias nuances de sua operação historiográfica. Tais nuances, aliás, podiam ser percebidas muito antes da fundação da USP: em 1911, em sua aula inaugural no curso de História Universal da Faculdade Livre de Filosofia e Letras de São Paulo, sua principal referência foi o livro de Langlois e Seignobos, Introduction aux études historiques (LANGLOIS; SEIGNOBOS 1992); contudo, mesmo falando sobre "Os princípios gerais da moderna crítica histórica", Taunay não deixou de criticar alguns pontos do método, como ao afirmar que:

[...] não era mais tempo de Histórias nacionais porque a disciplina exigia tamanho rigor metodológico que era impossível a um homem dar conta de pesquisar todos os temas do período em sua generalidade. Nesse sentido, considerou que aquele era o tempo das monografias (ANHEZINI 2011, p. 40-41).

Nesse sentido, considerar a tese de Alice Canabrava uma monografia demonstra o apreço de Taunay por este trabalho. Em suas palavras, "a monografia de D. Alice P. Canabrava é digna de real apreço e lugar de destaque Ihe fica assinalado nas resenhas bibliográficas sul-americanas, portuguesas e espanholas" (TAUNAY 1944, p. XI).

Outra crítica de Taunay à concepção historiográfica de Langlois e Seignobos diz respeito à sua recusa em aceitar a crítica deles à história da civilização (ANHEZINI 2011, p. 52). Destacamos como exemplo de que o historiador não deveria se restringir à história-batalha o fato de poder encontrar-se 23 anos 
depois, em seu texto para a cadeira de História da Civilização Brasileira, a seguinte fala:

Já não são a história militar e a administrativa as únicas que interessam aos autores e ao público. Incumbem-se os monografistas de apresentar entre aqueles assuntos os da história econômica e da religiosa, os da história literária, artística e científica e, sobretudo, o da história dos costumes (TAUNAY 1937, p. 123).

Na introdução da tese, a prof. a Alice explicita parte de seus objetivos: "[...] procuramos ventilar principalmente as questões econômicas suscitadas pela colonização espanhola na região platina [...]" (CANABRAVA 1944, p. XIII). Percebe-se a relação da professora com a proposta de Taunay de abordar assuntos de história econômica nas monografias e o fato de que a história não deve se restringir apenas ao registro das "campanhas militares". Assim, a autoridade concedida por Taunay a Alice Canabrava derivou de uma série de procedimentos historiográficos adotados por ela em sua tese e que foram propostos - ou, ao menos, defendidos - por Taunay: um estudo monográfico fundamentado em vasta documentação e que, escapando aos fatores da dita história-batalha, caracterizava-se como um estudo de história econômica.

Observamos que notórios intelectuais de origens distintas, como Afonso Taunay e Plínio Ayrosa, provenientes da tradição autodidata e vinculados ao IHGB, ao lado de Jean Gagé, Pierre Monbeig e Eurípedes Simões de Paula, já habituados com os métodos e práticas hauridos em um contexto de profissionalização do saber histórico e geográfico, aprovaram a tese de Alice Canabrava com distinção. E a historiadora também contou com a chancela de um importante membro da "missão francesa": Fernand Braudel, o que a qualificava para concorrer a uma das futuras cadeiras vacantes da subseção de Geografia e História da FFCL/USP.

\section{"O concurso"}

Desde 1938, Alice Canabrava era assistente de Paul Vanorden Shaw, que chegara da Universidade de Columbia para reger a cadeira de História da Civilização Americana. Em 1941, Shaw deixou a cadeira e Astrogildo Rodrigues de Mello foi designado para regê-la interinamente. Portanto, era preciso organizar novo concurso. Alice Canabrava relata que:

[...] em encontro casual com o professor André Dreyfus, Diretor da Faculdade de Filosofia, [ele] consultou-me sobre a possibilidade de concorrer ao concurso da cadeira de História da América, pois não desejava abri-lo para um único candidato, o professor contratado para a mesma (CANABRAVA 2005, p. 30).

Na fala de Dreyfus parece estar subjacente que não haveria problema algum em abrir o concurso apenas para um candidato, mas não soaria bem na comunidade acadêmica. Quando ele se realizou, entre os dias 30 de julho e 07 de agosto de 1946, apresentaram-se três candidatos: o regente interino Astrogildo Rodrigues de Mello, Odilon de Araujo Grellet, bacharel em Ciências 
Jurídicas e Sociais e professor do Ginásio Estadual Franklin Roosevelt, e Alice Canabrava, então assistente de Rodrigues de Mello. Dos cinco membros da banca examinadora, dois foram indicados pelo Conselho Universitário: Zeferino Vaz, da Faculdade de Medicina Veterinária, e Jorge Americano, da Faculdade de Direito; os outros três foram indicação da FFCL: Eremildo Luiz Vianna e Jaime Coelho, ambos da Faculdade Nacional de Filosofia (FNFi) da Universidade do Brasil (UB), no Rio de Janeiro, e Sérgio Buarque de Holanda, do Museu Paulista. Observando o boletim de notas concedidas aos candidatos pelos membros da banca examinadora para cada prova (títulos, escrita, didática e defesa de tese), temos os seguintes quadros: 8

Tabela 1 - Candidato Astrogildo Rodrigues de Mello. Média geral final: 9,25

\begin{tabular}{llllll}
\hline $\begin{array}{l}\text { Membros } \\
\text { da banca } \\
\text { examinadora }\end{array}$ & Títulos & $\begin{array}{l}\text { Prova } \\
\text { escrita }\end{array}$ & $\begin{array}{l}\text { Defesa de } \\
\text { tese }\end{array}$ & $\begin{array}{l}\text { Prova } \\
\text { didática }\end{array}$ & Média \\
\hline $\begin{array}{l}\text { Jorge } \\
\text { Americano }\end{array}$ & 10 & 9 & 9 & 9 & 9,25 \\
Zeferino Vaz & 10 & 9 & 8 & 9 & 9,00 \\
Jaime Coelho & 10 & 10 & 10 & 9 & 9,75 \\
$\begin{array}{l}\text { Eremildo Luiz } \\
\text { Vianna }\end{array}$ & 10 & 10 & 10 & 9 & 9,75 \\
$\begin{array}{l}\text { Sergio Buarque } \\
\text { de Holanda }\end{array}$ & 9 & 9 & 8 & 8 & 8,50 \\
\hline
\end{tabular}

Tabela 2 - Candidata Alice Piffer Canabrava. Média final geral: 9,35

\begin{tabular}{|c|c|c|c|c|c|}
\hline $\begin{array}{l}\text { Membros } \\
\text { da banca } \\
\text { examinadora }\end{array}$ & Títulos & $\begin{array}{l}\text { Prova } \\
\text { escrita }\end{array}$ & $\begin{array}{l}\text { Defesa de } \\
\text { tese }\end{array}$ & $\begin{array}{l}\text { Prova } \\
\text { didática }\end{array}$ & Média \\
\hline $\begin{array}{l}\text { Jorge } \\
\text { Americano }\end{array}$ & 9 & 9 & 10 & 9 & 9,25 \\
\hline Zeferino Vaz & 10 & 9 & 10 & 10 & 9,75 \\
\hline Jaime Coelho & 9 & 9 & 9 & 9 & 9,00 \\
\hline $\begin{array}{l}\text { Eremildo Luiz } \\
\text { Vianna }\end{array}$ & 9 & 9 & 9 & 9 & 9,00 \\
\hline $\begin{array}{l}\text { Sergio Buarque } \\
\text { de Holanda }\end{array}$ & 9 & 10 & 10 & 10 & 9,75 \\
\hline
\end{tabular}


Tabela 3 - Candidato Odilon de Araujo Grellet. Média final geral: 6,95

\begin{tabular}{|c|c|c|c|c|c|}
\hline $\begin{array}{l}\text { Membros } \\
\text { da banca } \\
\text { examinadora }\end{array}$ & Títulos & $\begin{array}{l}\text { Prova } \\
\text { escrita }\end{array}$ & $\begin{array}{l}\text { Defesa de } \\
\text { tese }\end{array}$ & $\begin{array}{l}\text { Prova } \\
\text { didática }\end{array}$ & Média \\
\hline $\begin{array}{l}\text { Jorge } \\
\text { Americano }\end{array}$ & 6 & 8 & 6 & 8 & 7 \\
\hline Zeferino Vaz & 6 & 8 & 6 & 8 & 7 \\
\hline Jaime Coelho & 6 & 8 & 6 & 8 & 7 \\
\hline $\begin{array}{l}\text { Eremildo Luiz } \\
\text { Vianna }\end{array}$ & 6 & 8 & 6 & 8 & 7 \\
\hline $\begin{array}{l}\text { Sergio Buarque } \\
\text { de Holanda }\end{array}$ & 6 & 8 & 6 & 7 & 6,75 \\
\hline
\end{tabular}

A média final geral de cada candidato foi feita pelo somatório das médias atribuídas por cada membro da banca examinadora e dividida por cinco, ou seja, pelo número de membros da banca. Desta forma, como se vê, tem-se que a média final geral mais elevada é a de Alice Piffer Canabrava, com 9,35. Contudo, no parecer final da comissão examinadora, datado de 7 de agosto de 1946, encontra-se o seguinte:

Por esses quadros, verifica-se que os candidatos Srs. Astrogildo Rodrigues de Mello e Alice Piffer Canabrava, obtiveram média igual, isto é, 9,25, consequente das notas atribuídas pelo Presidente da Comissão, Prof. Jorge Americano. Este, entretanto, depois de verificado o empate, declarou que desempatava em favor do Sr. Astrogildo Rodrigues de Mello, considerando achar-se este cátedra, digo, candidato na regência da cátedra, em comissão, de História da Civilização Americana (PROCESSO 1946, p. 1).

No parecer final, foram levadas em consideração somente as notas do presidente da banca, Jorge Americano, uma vez que um dispositivo do edital o permitia:

Tabela 4 - Parecer final

\begin{tabular}{|c|c|c|c|c|c|}
\hline Candidatos & Títulos & $\begin{array}{l}\text { Prova } \\
\text { escrita }\end{array}$ & Defesa tese & $\begin{array}{l}\text { Prova } \\
\text { didática }\end{array}$ & Média \\
\hline $\begin{array}{l}\text { Astrogildo } \\
\text { Rodrigues de Mello }\end{array}$ & 10 & 9 & 9 & 9 & 9,25 \\
\hline $\begin{array}{l}\text { Odilon de Araujo } \\
\text { Grellet }\end{array}$ & 6 & 8 & 6 & 8 & 7,00 \\
\hline $\begin{array}{l}\text { Alice Piffer } \\
\text { Canabrava }\end{array}$ & 9 & 9 & 10 & 9 & 9,25 \\
\hline
\end{tabular}

Segundo as notas por ele atribuídas, as médias finais de Astrogildo Rodrigues de Mello e de Alice Piffer Canabrava foram iguais, 9,25, e de Odilon de Araujo Grellet, 7,00. Ademais, na apreciação dos títulos, encontra-se o seguinte parecer: 
Dos três candidatos inscritos, é de mister salientar os excelentes títulos dos Srs. Astrogildo Rodrigues de Mello e Alice Piffer Canabrava. Ambos são portadores de diploma de licenciados, obtiveram doutoramento em História e têm exercício no magistério de ensino superior da Cadeira a que ora concorrem. Cumpre salientar, ademais, que publicaram trabalhos valiosos no domínio da História da América. [...] Entre os Srs. Astrogildo Rodrigues de Mello e Alice P. Canabrava há, a favor do primeiro, a circunstância de ocupar o cargo de Professor em comissão de H. da Civilização Americana e possuir o título de bacharel em Ciências Jurídicas e Sociais, enquanto a Profa. Alice Canabrava é assistente do mesmo, não tendo feito o curso jurídico, que é de grande auxílio para melhor entendimento dos problemas históricos, como, por exemplo, no tocante ao estudo das instituições políticas, sociais e econômicas (PROCESSO 1946).

No arrazoado do presidente da banca, pode parecer inusitada a afirmação de que o curso jurídico contribuiria para o melhor desempenho das funções de professor catedrático de História da Civilização Americana. Contudo, naquela cultura acadêmica, a tradição bacharelesca possuía grande peso. Como sugere Lidiane Rodrigues ao examinar as trajetórias de Alfredo Ellis Jr., Eurípedes Simões de Paula e Eduardo D'Oliveira França, o fato de esses três historiadores terem cursado a Faculdade de Direito os teria habilitado e legitimado a assumir cátedras na $\mathrm{FFCL}$, principalmente com a anuência, quando não interferência, de Fernand Braudel:

No que se refira a dimensões factuais e sociais, ficaram ocultadas as trajetórias femininas. Ao que tudo indica, o interdito a elas não era oriundo de Fernand Braudel. Possivelmente ele estivesse atrelado aos compromissos assumidos com a elite contratante. Vocalizando os valores dela, um expressivo depoimento de João Cruz Costa - que auxiliou o missionário em sua aclimatação no Brasil: "Isso de cátedras com catedráticos femininos não me parece coisa séria". Ademais, a pesquisa sugere que outros atributos, além da oposição homem/mulher, estivessem em jogo nas disputas, por exemplo, a origem "comissionada" ou já capitalizada culturalmente. A investigar (RODRIGUES 2013, p. 99).

Efetivamente, todos os que sucederam aos professores estrangeiros nas cátedras de História haviam passado pela Faculdade de Direito do Largo São Francisco: Eduardo D'Oliveira França substituiu Émile Léonard na cadeira de História da Civilização; Eurípedes Simões de Paula substituiu Jean Gagé na cadeira de História da Civilização Antiga e Medieval e Astrogildo Rodrigues de Mello substituiu Paul Vanorden Shaw na cadeira de História da Civilização Americana. No caso da cadeira de História da Civilização Brasileira, Alfredo Ellis Júnior também havia cursado a Faculdade de Direito quando sucedeu Afonso Taunay. Já quanto às relações de gênero, têm-se alguns relatos das hostilidades em relação à mulher na FFCL. Em entrevista concedida em 2001 ao projeto de Hélgio Trindade acerca da institucionalização das Ciências Sociais no Brasil, América Latina e França, a socióloga Heleieth Saffioti, quando questionada acerca de quem ministrava o curso de Sociologia na FFCL durante sua graduação (1956-1960), afirma que: 
Era o Fernando Henrique [Cardoso] e o Octavio Ianni. Havia a Maria Sylvia [de Carvalho Franco], que sofreu discriminações pelo fato de ser mulher. Inteligente ela é. Aquele livro dela, Homens livres na sociedade escravocrata, só recentemente que foi editado por uma editora comercial. Antes tinha sido editado por uma editora ligada à Maria Isaura [Pereira de Queiroz], que era amiga da Maria Sylvia e conseguiu publicar, porque o Fernando Henrique e o Ianni dominavam todas as editoras (SAFFIOTI 2012, p. 140).

Para além da oposição homem/mulher, Rodrigues (2013) também chama a atenção para a origem social dos catedráticos que sucederam aos professores estrangeiros. Ser mulher, entretanto, pesava mais naquela cultura acadêmica, uma vez que mesmo mulheres capitalizadas social e culturalmente, como Gilda de Mello e Souza, enfrentaram as hostilidades do grupo masculino. Heloisa Pontes, ao citar as mulheres que participaram do grupo "Clima", destaca Maria de Lourdes dos Santos, Ruth Alcântara e a própria Gilda, então ainda Moraes Rocha. Todas as mulheres tiveram um papel subsidiário no grupo, principalmente como secretárias de seus respectivos maridos, com exceção de Gilda, que tentou trilhar o caminho da escrita ficcional e acabou por seguir a carreira acadêmica.

De todas as mulheres do grupo, Gilda foi a única que conseguiu conciliar o trabalho e as atribuições domésticas com a carreira universitária. Diferentemente de Maria Lourdes, que como ela também se profissionalizou na Universidade de São Paulo, Gilda não abriu mão de seus projetos intelectuais e da vontade de escrever (PONTES 1998, p. 127).

Ainda no seu caso, o fato de ser mulher e ter escolhido uma temática "de mulher" para sua tese de doutoramento ("O espírito das roupas", apresentada em 1950), fizeram com que fosse preterida na sucessão da cadeira de Sociologia I, regida por Roger Bastide, seu orientador de tese, em favor de Florestan Fernandes (PONTES 2006, p. 90). Referindo-se a seu ambiente familiar tradicional, tanto em Araraquara quanto na capital paulista, para onde se mudou com 12 anos de idade para dar prosseguimento aos estudos, Gilda relata que parte daquilo de que fugia, e que era oriundo exatamente daquelas tradições, acabava por reencontrar na FFCL em seus colegas de curso:

$\mathrm{Na}$ verdade, o antigo preconceito masculino de que eu havia fugido se infiltrara renitente, se bem que mais brando, entre os próprios colegas de curso. Um ou outro talvez acreditasse sinceramente nas vocações intelectuais femininas, mas a maioria achava que qualquer prognóstico sobre nós era prematuro, pois ainda não tínhamos feito a escolha "essencial" - igual para todos -, aquela que, a seu tempo, iria revogar as demais: a escolha do marido. Não raro víamos aflorar formas mais agressivas de resistência, a suspeita, por exemplo, de que a nossa inquietação fosse estacional, derivasse apenas de uma privação afetiva. Passaria com o tempo sem deixar sequelas, como o sarampo e a coqueluche. Muitos talvez nem se lembrem desse juízo simplista - para não dizer simplório de nossas perplexidades (SOUZA 2004, p. 69-70).

Fechada essa digressão, outro aspecto que chama a atenção nas atas do concurso de 1946 são as notas atribuídas por Sérgio Buarque de Holanda às três 
teses apresentadas: 6 para Odilon Grellet, 8 para Astrogildo de Mello e 10 para Alice Canabrava. Este claro indício da superioridade da tese apresentada pela candidata revela também o grande apreço que o então diretor do Museu Paulista nutria pelo trabalho intelectual de Canabrava. Em ao menos quatro ocasiões posteriores tal apreço voltaria a aparecer: a primeira foi em artigo intitulado "Sobre o Colloquium", publicado no jornal Diário Carioca em 12 de novembro de 1950 (HOLANDA 2011, p. 55); a segunda, em "O pensamento histórico no Brasil nos últimos cinquenta anos", publicado em 15 de julho de 1951 no jornal Correio da Manhã (HOLANDA 2008, p. 614); a terceira, ao tratar de "História Econômica" no mesmo jornal, em 24 de agosto de 1952 (HOLANDA 2004, p. 138); e, por fim, em "Portugueses na América", artigo publicado em 09 de maio de 1959 no jornal O Estado de S. Paulo (HOLANDA 2011a, p. 279).

Destas quatro oportunidades, Alice Canabrava foi mencionada pontualmente em três; "História Econômica", por sua vez, é todo dedicado a ela, estabelecendo-a como sinônimo dessa especialidade. E o trabalho mais comentado por Sérgio Buarque neste artigo é exatamente a sua tese para a cadeira de História da Civilização Americana:

Da leitura dessa obra, apoiada numa impressionante bibliografia de impressos, além de copioso material manuscrito obtido de instituições como a Library of Congress de Washington ou a biblioteca da American Jewish Association de Nova York, sem falar nos arquivos brasileiros, e que representam um trabalho em muitos pontos sem antecedentes e verdadeiramente sem modelo em nossa literatura histórica [...] (HOLANDA 2004, p. 138).

Decerto por conta dessas características, a candidatura de Alice Canabrava à cadeira de História da Civilização Americana era vista como uma ameaça. Em suas memórias, ela relata que, depois que defendeu sua tese de doutoramento e despontou como possível candidata à cátedra, todos os catedráticos se voltaram contra ela:

[...] involuntariamente emergi, aos olhos dos meus colegas masculinos, como possível candidata ao provimento efetivo da cadeira de História da América, a ser posta em concurso. Até então, o relacionamento com esses colegas havia sido muito afável, direi até, não isento de estima pessoal (CANABRAVA 2005, p. 30).

Segundo Canabrava, vis-à-vis as notas de Jorge Americano, que empataram o concurso, o regulamento estipulava que todos os membros da banca deveriam votar em um candidato para que ficasse em primeiro lugar. Dois deles votaram em Astrogildo Rodrigues de Mello e dois em Alice Canabrava; com o desempate nas mãos do presidente, a escolha recaiu sobre Rodrigues de Mello. Anos mais tarde, Alice diria que:

[Jorge Americano] me mandou dizer que ele achava que o único erro na vida universitária profissional dele tinha sido decidir o concurso em favor da outra pessoa e não pra mim, mas que eu quisesse compreender que deram informações completamente erradas. Disseram que o outro 
candidato sofria de uma doença incurável e que por isso ficaria logo na pequena cátedra. E eu mandei dizer pela mesma pessoa que ele não tivesse nenhum remorso, que estava tão feliz onde estava. Que por mãos tortas, linhas transversas, eu tinha encontrado um excelente caminho (CANABRAVA 1981a). ${ }^{9}$

Tais afirmações sugerem que os professores do curso haviam combinado um resultado para que Astrogildo Rodrigues de Mello assumisse a cátedra, contando com seu afastamento pouco tempo depois. Contudo, tal estratégia não passara de um engodo para ludibriar o então reitor Jorge Americano e evitar que uma mulher assumisse a cátedra. Tendo em perspectiva a posição de Sérgio Buarque de Holanda, que atribuiu maiores notas à tese de Alice Canabrava e não à de Rodrigues de Mello, pode-se intuir que os dois professores da FNFi, Eremildo Luiz Vianna e Jayme Coelho, talvez não quiseram se comprometer com uma disputa de poder interna à subseção de Geografia e História da FFCL/USP e preferiram "votar juntos", uma vez que todas as notas por eles atribuídas aos candidatos, em todos os critérios, foram as mesmas. Podemos deduzir, assim, que os dois votos em favor do vencedor foram conferidos por Jayme Coelho e Eremildo Vianna, e que Sérgio Buarque de Holanda e Zeferino Vaz votaram em Alice Canabrava.

O depoimento de Olga Pantaleão, que também sofreu com as articulações do grupo masculino, é bastante esclarecedor dessa situação:

Finalmente, a Cátedra, posto final na carreira universitária na época, estava bem fora do alcance das mulheres: erguia-se uma muralha masculina contra a simples possibilidade. Nos anos 40, a única mulher catedrática na Congregação da Faculdade de Filosofia foi Noemy Silveira Rudolfer, que viera transferida do Instituto de Educação quando este foi extinto e, portanto, não tivera de pleitear a Cátedra. Durante quase um ano, de julho de 1946 a junho de 1947, mais uma mulher, eu mesma, pôde aparecer nesse quadro, regendo interinamente a Cadeira de História da Civilização Moderna e Contemporânea. Durou pouco tempo: por pressão e ação do grupo masculino dominante no curso de Geografia e História tive de deixar a Faculdade, tendo feito o restante de minha carreira fora da USP. E, finalmente, uma mulher fez o concurso para a Cátedra de História da Civilização Americana: Alice Piffer Canabrava. Foi um acontecimento! Mas, apesar de ter obtido as melhores notas, não ganhou o concurso: a banca examinadora escolheu o segundo colocado em notas, homem, naturalmente, dando-Ihe a Cátedra; esse absurdo era possível, então, por força do regulamento do concurso, o qual permitia à banca votar no candidato que ficaria em primeiro lugar. Isso foi tudo o que aconteceu, na década de 40, referente à ocupação da Cátedra pelas mulheres. Tudo bem ingressar na graduação por comissionamento; ser assistente; realizar doutoramento, mas, "tudo menos a Cátedra!" (PANTALEÃO 2004, p. 113-114).

Após o concurso, Alice Canabrava pediria demissão, pois não suportaria continuar como assistente de Astrogildo Rodrigues de Mello, e instalou-se

\footnotetext{
${ }_{9}^{9}$ Depoimento de Alice Piffer Canabrava ao Museu da Imagem e do Som de São Paulo, 1981. A referência do excerto reproduzido acima é: 00035EBR00027AD (Estudos Brasileiros, rolo 116.28 A-0151, número de Tombo 116.28).
} 
na recém-inaugurada FCEA. Um novo momento se abria em sua trajetória acadêmica e intelectual.

\section{A (con)sagração na Faculdade de Ciências Econômicas e Administrativas}

No mesmo ano de 1946, Alice Canabrava foi convidada a integrar a nova faculdade por indicação do diretor da FCEA, José Reis, ao reitor da USP:

Tenho a honra de propor à Vossa Magnificência a nomeação de Dra. ALICE PIFFER CANABRAVA para exercer cargo de Técnico de Administração, padrão N, da tabela II da Parte Permanente do Quadro do Ensino, criado pelo Decreto-lei n. ${ }^{\circ} 15$ 604, de 11 de Fevereiro de 1946, e lotado no Instituto de Administração, desta Faculdade, onde a interessada irá realizar trabalhos de investigação e pesquisa relativos à história da administração (PROCESSO 1946a, Ofício n. 58).

Após o trâmite burocrático junto ao interventor federal no Estado de São Paulo, Alice Canabrava foi nomeada para o setor de História do Instituto de Administração da FCEA, anexo à cadeira de Ciências da Administração. Sua função está descrita claramente: realizar pesquisas em História da Administração. Preterida no concurso da FFCL, ela agora construía uma nova rede de sociabilidade em sua também nova casa, onde, em 1951, chegaria enfim à cátedra, com a tese "O Desenvolvimento da Cultura do Algodão na Província de São Paulo (1861-1875)". Neste concurso em que foi única candidata, a aprovação veio de seus pares Afonso Taunay, Sérgio Buarque de Holanda, Paul Hugon (catedrático de Economia Política e História das Doutrinas Econômicas da FFCL e FCEA), José Joaquim Cardoso de Mello Neto (do curso de Economia Política da Faculdade de Direito e presidente da banca) e Theotonio Monteiro de Barros Filho (diretor da FCEA). Na ata do concurso da cadeira de número $\mathrm{X}$, de História Econômica, encontramos as seguintes notas atribuídas pelos membros da banca examinadora: ${ }^{10}$

Tabela 5 - Notas atribuídas pela banca examinadora. Média final geral: 8,75

\begin{tabular}{llllll}
\hline $\begin{array}{l}\text { Membros } \\
\text { da banca } \\
\text { examinadora }\end{array}$ & Títulos & $\begin{array}{l}\text { Prova } \\
\text { escrita }\end{array}$ & $\begin{array}{l}\text { Arguição } \\
\text { sobre a tese }\end{array}$ & $\begin{array}{l}\text { Prova } \\
\text { didática }\end{array}$ & Média \\
\hline $\begin{array}{l}\text { J. J. Cardoso } \\
\text { de Mello Neto }\end{array}$ & 9 & 9 & 8 & 8 & 8,5 \\
$\begin{array}{l}\text { Afonso Taunay } \\
\text { Paul Hugon }\end{array}$ & 10 & 9 & 9 & 9 & 9 \\
$\begin{array}{l}\text { Sergio B. de } \\
\text { Holanda }\end{array}$ & 10 & 9 & 8 & 9 & 9,25 \\
$\begin{array}{l}\text { Theotônio } \\
\text { Monteiro }\end{array}$ & 9 & 7 & 8 & 9 & 8,75 \\
\hline
\end{tabular}

\footnotetext{
10 Tabela elaborada a partir das notas atribuídas pelos membros da banca examinadora. Cf. processo $\mathrm{n}$. 51.1.12250.1.8 (arquivo da Reitoria da USP), conforme as atas do concurso. Estas notas encontram-se na página 6.
} 
Como vimos, Alice Canabrava entendia os procedimentos de escrita da história de modo próximo às principais concepções de Afonso Taunay acerca do trabalho historiográfico. Além disso, havia o prestígio que seu trabalho obtivera junto ao professor Sérgio Buarque de Holanda, que, além de diretor do Museu Paulista, à época também atuava como professor de História Econômica na Escola Livre de Sociologia e Política de São Paulo (NICODEMO 2012, p. 115). Suas palavras davam ao trabalho da professora, agora da FCEA, uma legitimidade sem par, desfazendo quaisquer resquícios de mal-entendidos que tivessem sido gerados pelo malfadado concurso em que fora reprovada. Agora, sua aprovação na FCEA, que a tornou a primeira mulher catedrática da história da USP, estava de acordo com as diretrizes historiográficas de seus mestres Afonso Taunay e Sérgio Buarque de Holanda, bem como com os embasamentos constantes na tese de história econômica sob a perspectiva de Paul Hugon. Consta nas atas dos arquivos que, diante de grande assistência, Alice Piffer Canabrava foi aclamada catedrática da cadeira de número $X$ da FCEA. Chegara o momento da "derrota" de 1946 se transformar em consagração.

A destacada carreira construída nesta Faculdade não seria capaz, contudo, de apagar completamente a mágoa pelo que ocorrera na FFCL. Exatos 35 anos depois, em carta para o amigo Francisco Iglésias, ela assim se referia à publicação em livro de sua tese de livre-docência, ocorrida naquele mesmo ano:

Demorei muitos anos para pensar na reedição, ou melhor, na edição, desde que a primeira versão constou apenas de 100 exemplares mimeografados para cumprir regulamento de concurso. Durante tantos anos não conseguia sequer abrir o meu exemplar. Trauma do concurso. Também nunca ia à Faculdade de Filosofia. Aos poucos fui sublimando. A verdade é que durante muito tempo sonhei com o concurso, em várias versões, eu sempre em situação difícil. A razão de tudo: eu havia sofrido muito com a perseguição, a Faculdade inteira contra mim, o próprio concurso, o meu pedido de demissão da Faculdade, minha ida para uma outra instituição universitária recémcriada. Tudo foi sofrimento, ainda que, um grande passo para melhor, e hoje, a distância no tempo, pode apreciar muito bem o que significou para minha vida. E posso repetir sua afirmação, também foi o único bilhete de Loteria que me foi dado ganhar em toda a minha vida, ir para a Faculdade de Economia. Ainda há pouco, na sessão solene do Departamento/Congregação, para minha despedida, deixei registrado que muito devo à Faculdade de Economia e tenho por ela um grande apego afetivo. ${ }^{11}$

Em outra carta também endereçada ao historiador mineiro, esta de 1982, a propósito da morte de Sérgio Buarque de Holanda, ela escreveu:

A sugestão de seu nome [Francisco Iglésias] para sucedê-lo na Faculdade de Filosofia é um exemplo, seu nome brotava espontaneamente de muitos aos quais ele [Sérgio Buarque] dava expressão. Para a Fac. Filosofia foi pena que $\mathrm{V}$. não aceitasse, embora tenha eu de reconhecer que para $\mathrm{V}$. como pessoa e como historiador, foi uma sábia decisão manter-se longe do "ninho de víboras". ${ }^{12}$

\footnotetext{
${ }_{11}$ CCarta de Alice P. Canabrava a Francisco Iglésias. São Paulo, 31 de dezembro de 1981. Acervo de Alice Piffer Canabrava, Instituto de Estudos Brasileiros (IEB/USP): APC CP - P1-28-(4), p. 1.

12 Carta de Alice P. Canabrava a Francisco Iglésias. São Paulo, 29 de abril de 1982. Acervo de Alice Piffer
} 


\section{Considerações finais}

Em tempos idos, mas não tão distantes, eram imensas as dificuldades das mulheres que visavam a alcançar o mais alto posto da carreira acadêmica na FFCL-USP: a cátedra. Deparamo-nos aqui com os anos 1940, momento em que Alice Canabrava, como também Olga Pantaleão, enfrentaram as barreiras criadas pelos intelectuais masculinos. Nos anos 1950, foi a vez de outra grande pesquisadora, Gilda de Mello e Souza, se defrontar com elas, que permaneceriam pelo menos até a década seguinte: em 1967, Paula Beiguelman foi outra preterida, desta vez em concurso para a cadeira de Política em 1968, que alçou Fernando Henrique Cardoso à cátedra. De acordo com Heloisa Pontes:

Deixando de lado a questão da competência dos candidatos envolvidos nesse concurso, é preciso ressaltar que Paula Beiguelman foi a segunda mulher (depois de Alice Canabrava) a disputar uma posição mais sólida na Faculdade de Filosofia (PONTES 1998, p. 199).

De fato, a assertiva de Pontes não é descabida, pois a comparação com o caso de Alice Canabrava é inevitável. Ainda mais quando se toma ciência de que ela própria, Alice Canabrava, fez questão de participar da banca examinadora do concurso de livre-docência de Paula Beiguelman. Em carta endereçada a Francisco Iglésias, datada de 17 de junho de 1967, a professora relata que, mesmo evitando participar de bancas examinadoras de concursos, uma vez que o seu sofrimento como candidata em duas delas ainda era muito presente, não poderia deixar de atender ao pedido de sua amiga Paula; em especial, porque Florestan Fernandes impunha seu imperialismo progressivamente, valendo-se das mais variadas articulações:

No caso particular do concurso da Paula, eu aceitei pela grande amizade e admiração que tenho pela Paula. Como tive oportunidade de dizer a ela, quando insistiu comigo pela aceitação (o meu primeiro gesto é recusar logo), eu me via impelida a aceitar a indicação, como uma imposição de amor, a que eu não podia fugir. Parecia-me também (o que eu não disse a ela) que seria omissão imperdoável de minha parte se eu não participasse do concurso para defender a Paula, sabendo que o Florestan Fernandes forçou sua própria participação na banca com o propósito de dificultar o mais possível o caminho de nossa amiga, para colocar na cadeira de Política um dos dois de seus assistentes: Fernando Henrique ou Octavio Ianni. ${ }^{13}$

Alice Piffer Canabrava, Olga Pantaleão, Gilda de Mello e Souza, Paula Beiguelman... Poder-se-ia citar muitas tantas mulheres que, durante suas notórias trajetórias intelectuais, em algum momento foram bloqueadas justamente pelo

\footnotetext{
Canabrava, Instituto de Estudos Brasileiros (IEB/USP): APC -Ca - P2, 11-(5).

${ }_{13}$ Carta de Alice P. Canabrava a Francisco Iglésias. São Paulo, 17 de junho de 1967. Acervo Francisco Iglésias, Instituto Moreira Salles (IMS-RJ): FI-C-CP (078), p. 4. Nesta mesma carta, Alice Canabrava relata que Florestan estava na banca e fez o que pôde para desqualificar a candidata, mas que esta foi aprovada. Contudo, Alice Canabrava não participou da banca do concurso para a cadeira de Política, em 1968, no qual Paula foi preterida e Fernando Henrique Cardoso saiu vitorioso. Nesta ocasião, a banca examinadora foi formada por Ruy Coelho e Sérgio Buarque de Holanda - indicados pela Congregação - e Orlando de Carvalho, José Honório Rodrigues e Victor Nunes Leal, indicados pelo Conselho Técnico-Administrativo (PINHEIRO 2016, p. 188).
} 
fato de serem mulheres e tentarem alçar postos que naquele período estavam tradicionalmente destinados aos homens. Mesmo que a sociedade visse com bons olhos o posto de professora, naquela cultura acadêmica das décadas iniciais da FFCL/USP a regência da cátedra por elementos femininos não era bem vista. Ou, "tudo, menos a cátedra!". Na percepção da própria Alice Canabrava,

[...] o ambiente da Faculdade de Economia era bem diferente do da Faculdade de Filosofia. Na Faculdade de Filosofia havia muitos "intelectualóides" que se diziam avançados, liberais, mas que, no fundo, eram extremamente preconceituosos para com a mulher (CANABRAVA 1997, p. 163).

Uma possível explicação para tal distinção pode ser encontrada nos intentos de criação da FFCL frente aos da FCEA. A primeira foi concebida com o fito de formar as elites dirigentes do país e colocar São Paulo como seu centro cultural e intelectual (CARDOSO 1982); a segunda foi gestada em outros moldes, ligados muito mais à formação de quadros técnicos em um contexto de intervenção do Estado na Economia, voltados à assessoria governamental e, posteriormente, ao setor privado. Assim, sua cultura acadêmica se aproxima mais das ditas faculdades profissionais, como Medicina, Engenharia, Direito e Agronomia, ainda que sem o peso da tradição das três primeiras. Por isso, Alice Canabrava nunca encontrou ali nenhum tipo de interdição por parte de seus colegas:

Sou muito grata à Faculdade de Economia e Administração (a nova designação com a reforma de 1970), na qual jamais encontrei a menor restrição, tanto eu como outras colegas, seja em trabalhos de docência como de pesquisa, e em funções administrativas (CANABRAVA 2005, p. 33).

Assim, ao destacar alguns pontos da trajetória intelectual de Alice Piffer Canabrava e esboçar algumas comparações com a trajetória de outras mulheres acadêmicas nos anos iniciais da FFCL-USP, esperamos ter demonstrado que os interditos às mulheres naquela ambientação institucional provinham de dupla fonte: a cultura acadêmica misógina predominante daquele momento e uma concepção arraigada acerca do papel social definido para a mulher. Em nosso entender, Alice Canabrava logrou sucesso na FCEA-USP exatamente pelo fato de que não se tratava apenas de outra Faculdade, mas, sobretudo de uma cultura acadêmica diferente.

\section{Referências bibliográficas}

ANHEZINI, Karina. Um metódico à brasileira: a história da historiografia de Afonso de Taunay (1911-1939). São Paulo: Unesp, 2011.

CANABRAVA, Alice Piffer. O comércio português no rio da Prata (1580-

1640). São Paulo: Faculdade de Filosofia, Ciências e Letras. Boletim XXXV. História da Civilização Americana. N. 2, 1944.

. Memorial. In: Processo 46.1.126.8.7, 1946. 
Açúcar nas Antilhas (1697-1755). 2. ed. São Paulo: Instituto de Pesquisas Econômicas, 1981.

. Depoimento. Museu da Imagem e do Som. Estudos Brasileiros, rolo 116.28 A-0151, número de Tombo 116.28, 1981a.

. Curriculum Vitae. São Paulo, 22 de Fevereiro de 1991.

Minhas reminiscências. Economia Aplicada. São Paulo, v. 1, n. 1, p. 157-163, 1997.

O caminho percorrido. In: História Econômica: estudos e pesquisas. São Paulo: Hucitec; Unesp; ABPHE, 2005, p. 23-34.

CANDIDO, Antonio. Conto de duas cidades. In: CALDEIRA, João Ricardo de Castro (Org.). Perfis buarqueanos: ensaios sobre Sérgio Buarque de Holanda. São Paulo: Fundação Memorial da América Latina; IMESP, 2005, p. 9-16.

CARDOSO, Irene. A universidade da comunhão paulista. O projeto de criação da Universidade de São Paulo. São Paulo: Cortez, 1982.

FREITAS, Sonia Maria de. Reminiscências. São Paulo: Maltese, 1993.

HARTOG, François. Introdução. In: A história, de Homero a Santo

Agostinho. Belo Horizonte: UFMG, 2001.

HOLANDA, Sérgio Buarque de. Para uma nova história. Organização de Marcos Costa. São Paulo: Ed. Fundação Perseu Abramo, 2004.

. O pensamento histórico nos últimos 50 anos. In: MONTEIRO, Pedro Meira; EUGÊNIO, João Kennedy (Org.). Sérgio Buarque de Holanda: perspectivas. Campinas: Ed. Unicamp; Rio de Janeiro: EdUERJ, 2008, p. 601-616.

Sobre o Colloquium. In: COSTA, Marcos (Org.). Escritos coligidos, 1950-1979. São Paulo: Editora Fundação Perseu Abramo; Editora UNESP, 2011.

. Portugueses na América. In: COSTA, Marcos (Org.). Escritos coligidos, 1950-1979. São Paulo: Ed. Fundação Perseu Abramo; Ed. UNESP, 2011 a. LANGLOIS, Charles-Victor \& SEIGNOBOS, Charles. Introduction aux études historiques. Paris: Éditions Kimé, 1992 [1898].

MELLO, Zélia Maria Cardoso de; NOZOE, Nelson Hideiki; SAES, Flávio Azevedo Marques de. Três Pesquisas Pioneiras em História Econômica (as teses universitárias de Alice Piffer Canabrava). Estudos Econômicos, v. 15, n. especial, p. 169-179, 1985.

NICODEMO, Thiago Lima. Sérgio Buarque de Holanda e a Dinâmica das Instituições Culturais no Brasil 1930-1960. In: MARRAS, Stelio. Atualidade de Sérgio Buarque de Holanda. São Paulo: EDUSP; IEB, 2012, p. 109-132. 
PANTALEÃO, Olga. Depoimentos. In: BLAY, Eva Alterman; LANG, Alice Beatriz da Silva Gordo. Mulheres na USP: horizontes que se abrem. São Paulo: Humanitas, 2004, p. 107-115.

PINHEIRO, Dimitri. Jogo de damas: trajetórias de mulheres nas ciências sociais paulistas (1934-1969). Cadernos Pagu, n. 46, p. 165-196, 2016.

PONTES, Heloisa. Destinos mistos: os críticos do Grupo Clima em São Paulo (1940-68). São Paulo: Companhia das Letras, 1998.

. A paixão pelas formas. Gilda de Mello e Souza. Novos Estudos, n. 74, p. 87-105, 2006.

Processo 46.1.325.8.0. Arquivo Faculdade de Filosofia, Letras e Ciências Humanas (FFLCH) da USP: concurso para a cátedra de História da Civilização Americana, 1946.

Processo 46.1.126.8.7. Arquivo FFLCH da USP: inscrição no concurso para a cadeira de História da Civilização Americana, 1946a.

Processo 51.1.12250.1.8. Arquivo Reitoria USP: concurso para a cadeira de História Econômica Geral da Faculdade de Ciências Econômicas e Administrativas, USP, 1951.

RINGER, Fritz K. Fields of knowledge: French academic culture in comparative perspective, 1890-1920. Cambridge: Cambridge University Press, 1992.

114 RODRIGUES, Lidiane Soares. Armadilha à francesa: homens sem profissão. História da Historiografia, n. 11, p. 85-103, 2013.

ROIZ, Diogo da Silva. Os caminhos (da escrita) da História e os descaminhos de seu ensino: a institucionalização do ensino universitário de História na Faculdade de Filosofia, Ciências e Letras da Universidade de São Paulo (1934-1968). Curitiba: Appris, 2012.

. A dialética entre o "intelectual-letrado" e o "letrado-intelectual": projetos, tensões e debates na escrita da História de Alfredo Ellis Jr. e Sérgio Buarque de Holanda (1929-1959). Tese (Doutorado em História) Programa de Pós-Graduação em História, Universidade Federal do Paraná, Curitiba, 2013.

SAFFIOTI, Heleieth. Entrevista. In: TRINDADE, Hélgio. Ciências Sociais no

Brasil: diálogos com mestres e discípulos. Brasília: Anpocs/Liber Livro Editora, 2012, p. 139-155.

SOUZA, Gilda de Mello e. Depoimento. In: BLAY, Eva Alterman; LANG, Alice Beatriz da Silva Gordo. Mulheres na USP: horizontes que se abrem. São Paulo: Humanitas, 2004, p. 61-75.

TAUNAY, Afonso E. A propósito do curso de História da Civilização Brasileira da Faculdade de Filosofia, Ciências e Letras. Anuário da Faculdade de Filosofia, Ciências e Letras, 1934-1935. São Paulo, FFCL-USP, 1937, p. $122-131$. 
Prefácio. In: CANABRAVA, Alice Piffer. 0 comércio português no rio da Prata (1580-1640). São Paulo: Faculdade de Filosofia, Ciências e Letras, 1944. (Boletim XXXV, História da Civilização Americana, n. 2).

TRINDADE, Hélgio. Ciências Sociais no Brasil: diálogos com mestres e discípulos. Brasília: Anpocs; Liber Livro, 2012. 